\title{
CHEMO-IMMUNOLOGICAL STUDIES ON CONJUGATED CARBOHYDRATE-PROTEINS
}

IX. The Specificity of Antigens Prepared by Combining the p-Aminophenol Glycosides of Disaccharmes with Protein

By WALTHER F. GOEBEL, Ph.D., OSWALD T. AVERY, M.D., AND FRANK H. BABERS

(From the Hospital of The Rockefeller Institute for Medical Research)

(Received for publication, August 9, 1934)

As a result of the work of numerous investigators a striking advance has been made during the past decade in our knowledge of the chemical and immunological properties of that unique class of naturally occurring substances, the specific bacterial polysaccharides. Complex carbohydrates possessing immunologically specific properties have been found widely distributed in many varieties of different microorganisms. The significance of these findings lies in the fact that these specific components, having in common the chemical properties of polysaccharides, are known to function as determinant substances in many of the specific reactions of bacterial infection and immunity. The fact that these carbohydrates, so closely related in chemical properties, remain sharply differentiated in biological specificity may eventually be explained on the basis of certain subtle differences in the chemical structure of the molecules that constitute these substances. Possible differences in stereochemical structure and in the position of intermolecular linkages between the individual sugars comprising the polysaccharides are manifold. Indeed, it is not unlikely that structural differences of this character account for the wide variation in the immunological specificity exhibited by carbohydrates of diverse origin.

It is already known that differences in the stereochemical structure of the carbohydrate radical in artifically compounded hexoside-protein antigens influence their immunological specificity (1). It has been shown that the azophenol glycosides of glucose and galactose, irrespective of the protein with which they are combined, give rise in the 
animal body to the formation of antibodies which are distinct and specific for the carbohydrate radical in the antigenic complex. Although the difference in chemical structure between the glycosides of glucose and galactose is confined to an interchange of the $\mathrm{H}$ and $\mathrm{OH}$ groups on the fourth carbon atom of the hexose radical, yet this slight alteration in chemical configuration suffices to determine the biological specificity of antigens containing these hexosides. If, on the other hand, the structural differences in monosaccharides be confined to the carbon atom bearing the aglucon, as in antigens containing $\alpha$ and $\beta$-azophenol glucosides, then the immunological reactions of these two derivatives of glucose, though predominantly type-specific, show a certain degree of crossing, presumably attributable to the identity in structure of the five terminal carbon atoms of both glucosides (2).

Thus it has been established experimentally that the stereochemical configuration of the hexose radical has an important influence in determining the biological specificity of artificial antigens containing simple monosaccharides. Whether stereochemical changes in the hexose constituents of more complex saccharides exert a similar influence, and whether the position of linkage of hexose to hexose affects the course of antibody response, are questions of importance in elucidating the factors which govern the specificity of the reactive polysaccharides of bacterial origin.

The disaccharides are substances of known chemical constitutions, and hence are excellent derivatives to use in studying the influence of changes in intermolecular linkage and stereochemical structure on biological specificity. For this purpose, therefore, the $p$-aminophenol glycosides of lactose, gentiobiose, cellobiose, and maltose have been synthesized (3). The diazonium derivatives of these glycosides have been combined with protein and the resulting conjoined disaccharideproteins have been utilized as antigens in the preparation of immune rabbit sera. The present paper is an account of the immunological properties of these artifically conjugated antigens. For purposes of comparison there are also included the serological properties of antigens containing monosaccharide derivatives prepared by combining with the same protein the $p$-aminophenol glycosides of $\alpha$ - and $\beta$ glucose and of $\beta$-galactose. 


\section{EXPERIMENTAI}

1. Methods.-The methods of preparing the mono- and disaccharide immunizing antigens used in the present study differ in no essential respect from those previously described $(2 b)$. The method of intravenous immunization of rabbits, and the technique of the precipitin and inhibition tests, are the same as those employed in earlier studies. The immunizing antigens were prepared by combining each of the carbohydrate derivatives with the globulin of normal horse serum. In order to avoid the reactions of a common protein, the test antigens were similarly prepared by combining the same glycosides to the protein of chicken serum.

For purposes of brevity the p-aminophenol glycosides of the different sugars will be frequently referred to throughout the text and tables by the following abbreviations: $\alpha=\alpha$-glucoside; $\beta=\beta$-glucoside; $\mathrm{Ga}=\beta$-galactoside; $\mathrm{C}=\beta$ cellobioside; $\mathrm{M}=\beta$-maltoside $; \mathrm{Ge}=\beta$-gentiobioside; and $\mathrm{L}=\beta$-lactoside. The immunizing antigens prepared by combining these glycosides with globulin are referred to as $\alpha$-globulin, C-globulin, etc., and the corresponding antisera respectively as $\alpha$-antiserum, C-antiserum, etc. The test antigens, prepared by combining the glycosides with chicken serum protein are designated as $\alpha$-test antigen, C-test antigen, etc.

\section{Specific Precipitin Tests}

1. Homologous Precipitin Reactions of Mono- and Disaccharide Antisera.-The sera of rabbits immunized respectively with antigens containing the three monosaccharide and the four disaccharide glycosides combined with horse serum globulin were first studied for the presence of homologous precipitins. Test antigens containing the same glycosides combined with the protein of chicken serum were used in the precipitation tests. The results of these tests are given in Table I.

From the results presented in Table $I$ it is seen that antigens containing either mono- or disaccharide radicals give rise in each instance to immune bodies which react with the same carbohydrate derivative irrespective of the protein to which it is attached. The glycosideproteins function as effective antigens in the animal body, and it is suggested that the large number of polar $(\mathrm{OH})$ groups in the carbohydrate radical may account for this fact.

2. Heterologous Precipitin Reactions of the Disaccharide Antisera. In order to ascertain whether the disaccharide antisera cross-react with test antigens containing the other disaccharides, each serum was tested for the presence of heterologous precipitins.

The results of the cross-precipitin tests are summarized in Table II. 
From the results given in Table II, it can be seen that an antiserum prepared by immunization with $\mathrm{C}$-globulin contains antibodies which precipitate not only the homologous C-test antigen, but the heterologous Ge-test antigen as well. Similarly the antiserum to Ge-globulin contains precipitins for the homologous test antigen and cross-reacts with the heterologous C-test antigen. Neither of these antisera, however, reacts to any appreciable extent with test antigens con-

TABLE I

Homologous Precipitin Reactions of Mono- and Disaccharide Antisera*

\begin{tabular}{|c|c|c|c|c|c|c|}
\hline \multirow{2}{*}{$\begin{array}{l}\text { Antisera prepared by } \\
\text { immunization with: }\end{array}$} & \multirow{2}{*}{\multicolumn{2}{|c|}{ Test antigens $\dagger$}} & \multicolumn{4}{|c|}{ Final dilution of test antigens } \\
\hline & & & $1: 5,000$ & $1: 10,000$ & $1: 20,000$ & $1: 40,000$ \\
\hline \multirow{2}{*}{$\alpha$-Globulin } & \multirow{2}{*}{\multicolumn{2}{|c|}{${ }_{\beta}^{\alpha}$ Chicken serum }} & +++ \pm & +++ \pm & ++ \pm & ++ \\
\hline & & & $+t+t$ & $+t+t$ & +++ & $+t+$ \\
\hline $\mathrm{Ga}$ “ & $\mathrm{Ga} \approx$ & “ & $t+t \pm$ & $+t+$ & $+t \pm$ & $+t$ \\
\hline C " & $\mathrm{C}$ & “ & $+t+t$ & $t+t+$ & $t+t \pm$ & $+t+$ \\
\hline M “ & & “ & $+t+t$ & $+t+t$ & $t+t+$ & $++t$ \\
\hline $\mathrm{Ge}$ “ & $\mathrm{Ge}$ " & “ & $t+t \pm$ & $+t+$ & $+t+$ & $+t \pm$ \\
\hline L $\quad$ " & $\mathrm{L}$ & “ & $+t+t$ & $++t \pm$ & +++ & ++ \pm \\
\hline
\end{tabular}

$++++=$ complete precipitation with compact disk formation.

$\pm=$ faint turbidity when read with artificial illumination against dark background.

$0=$ no precipitation.

* The immune sera were in all instances used in constant amounts of $0.2 \mathrm{cc}$. A dilution of serum in the proportion of two parts of serum to three parts of salt solution was prepared, and $0.5 \mathrm{cc}$. of this dilution, containing $0.2 \mathrm{cc}$. of the original serum, was added to $0.5 \mathrm{cc}$. of the varying dilutions of test antigens, in Tables I to IV.

† Test antigens were prepared by combining the respective glycosides with the protein of chicken serum.

taining $\mathrm{M}$ or $\mathrm{L}$. The $\mathrm{M}$-antiserum, on the other hand, precipitates not only $\mathbf{M}$ - but also Ge- and C-test antigens; the $\mathbf{M}$-antiserum does not react with test antigen containing $\mathrm{L}$. The L-globulin antiserum precipitates both the homologous and the heterologous C-test antigen; however, it does not react with test antigens in which $M$ or $\mathrm{Ge}$ is present.

The cross-precipitin reactions of these four disaccharide antisera 
appear at first difficult of interpretation, but further consideration of the stereochemical structures of the four glycosides affords an insight into the complexities of the cross-reactions. Each of the disaccharide glycosides has in common a large chemical grouping; namely, a glucose molecule substituted by the aglucon- $-\mathrm{C}_{6} \mathrm{H}_{4} \mathrm{~N}=\mathrm{N}-$ combined in glucosidic union with the reducing group of the hexose. In the case of the gentiobioside and cellobioside, each glycoside contains a terminal

TABLE II

Heterologous Precipitin Reactions of Disaccharide Antisera

\begin{tabular}{|c|c|c|c|c|c|c|}
\hline \multirow{2}{*}{$\begin{array}{l}\text { Antisera prepared by } \\
\text { immunization with: }\end{array}$} & \multirow{2}{*}{\multicolumn{3}{|c|}{ Test antigens }} & \multicolumn{3}{|c|}{ Final dilution of test antigens } \\
\hline & & & & $1: 5,000$ & $1: 10,000$ & $1: 20,000$ \\
\hline C-Globulin & $\begin{array}{l}\text { C } \\
\text { M } \\
\text { Ge } \\
\text { L }\end{array}$ & $\begin{array}{r}\text { Chicl } \\
6 \\
6 \\
،\end{array}$ & $\begin{array}{l}\text { erum } \\
\text { " } \\
" 6 \\
"\end{array}$ & $\begin{array}{c}+++t \\
\pm \\
++ \pm \\
\pm\end{array}$ & $\begin{array}{c}+++ \\
\pm \\
++ \\
\pm\end{array}$ & $\begin{array}{c}+++ \pm \\
\pm \\
+ \pm \\
\pm\end{array}$ \\
\hline M-Globulin & $\begin{array}{l}\mathrm{C} \\
\mathrm{M} \\
\mathrm{Ge} \\
\mathrm{L}\end{array}$ & $\begin{array}{r}\text { Chicl } \\
، \\
، \\
،\end{array}$ & $\begin{array}{l}\text { erum } \\
\text { " } \\
\text { " } \\
\text { " }\end{array}$ & $\begin{array}{c}+++ \\
++++ \\
++ \pm \\
\pm\end{array}$ & $\begin{array}{c}++ \pm \\
++++ \\
+ \pm \\
\pm\end{array}$ & $\begin{array}{c}+ \pm \\
+++ \pm \\
+ \\
\pm\end{array}$ \\
\hline Ge-Globulin & $\begin{array}{l}\mathrm{C} \\
\mathrm{M} \\
\mathrm{Ge} \\
\mathrm{L}\end{array}$ & $\begin{array}{r}\text { Chicl } \\
6 \\
4 \\
4\end{array}$ & $\begin{array}{l}\text { erum } \\
" \\
" \\
"\end{array}$ & $\begin{array}{c}+++ \\
\pm \\
++++ \\
\pm\end{array}$ & $\begin{array}{c}+++ \\
\pm \\
+++ \pm \\
\pm\end{array}$ & $\begin{array}{c}++ \\
\pm \\
++ \pm \\
\pm\end{array}$ \\
\hline L-Globulin & $\begin{array}{l}\text { C } \\
\text { M } \\
\text { Ge } \\
\text { L }\end{array}$ & $\begin{array}{r}\text { Chicl } \\
\text { " } \\
\text { " } \\
\text { " }\end{array}$ & $\begin{array}{l}\text { erum } \\
\text { " } \\
\text { " }\end{array}$ & $\begin{array}{c}++ \pm \\
\pm \\
\pm \\
+++ \pm\end{array}$ & $\begin{array}{c}++ \pm \\
\pm \\
\pm \\
+++\end{array}$ & $\begin{array}{c}++ \\
\pm \\
\pm \\
+++\end{array}$ \\
\hline
\end{tabular}

$\beta$-glucose molecule substituted in positions 6 and 4 respectively of the glucose molecule bearing the aglucon. The maltoside, on the other hand, has an $\alpha$-glucose molecule substituted in position 4 , whereas the lactoside has a $\beta$-galactose molecule in this same position. The constitutional and configurational relationships of these four glycosides may best be understood by the following graphic formulae: 
604 CONJUGATED CARBOHYDRATE-PROTEINS. IX

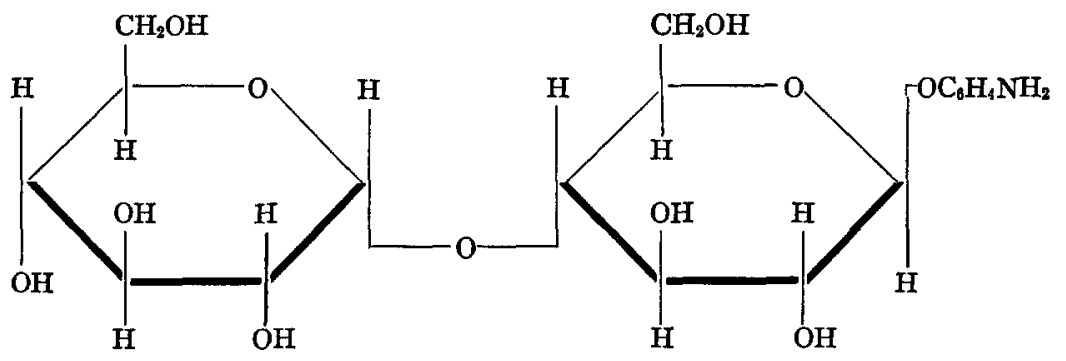

$p$-Aminophenol $\beta$-maltoside

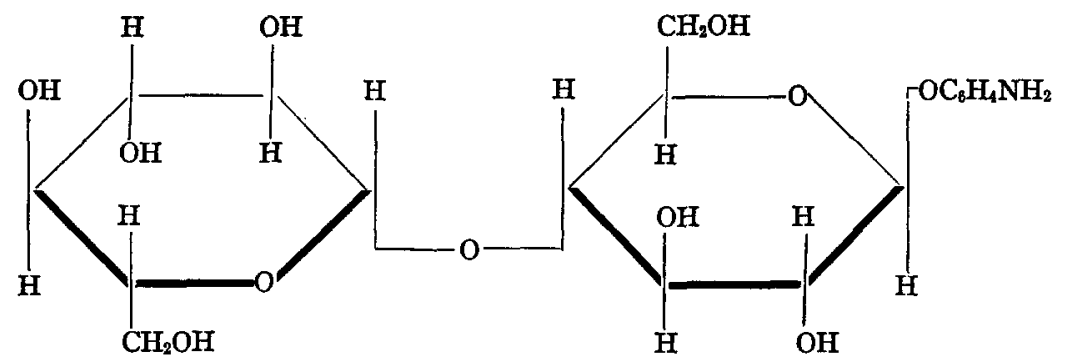

$p$-Aminophenol $\beta$-cellobioside

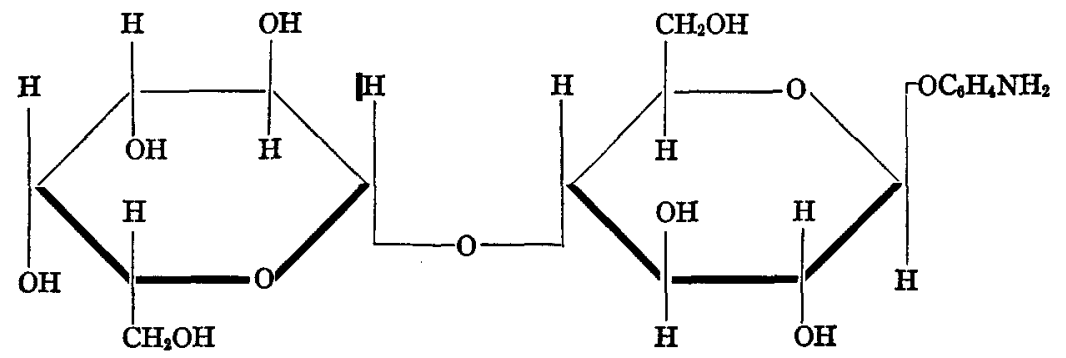

$p$-Aminophenol $\beta$-lactoside

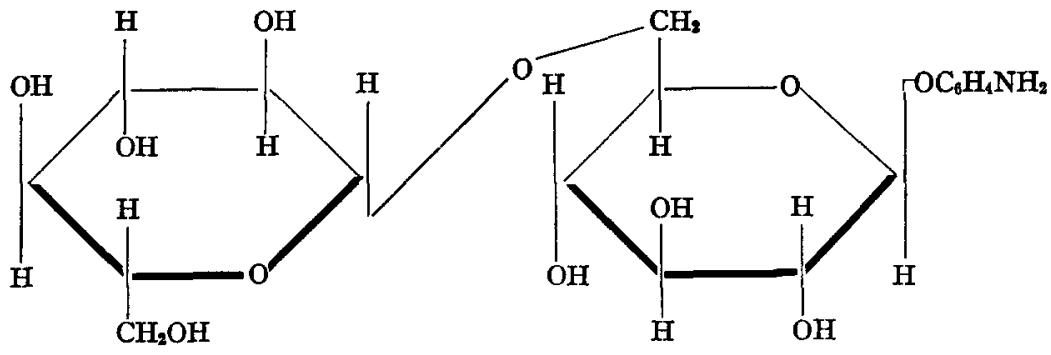

$p$-Aminophenol $\beta$-gentiobioside 
From the graphic formulae it can be seen that the carbohydrate radicals of the cellobioside and gentiobioside are each composed of two units of glucose combined in glucosidic union. In the case of the cellobioside, the union of hexose molecules is on the fourth carbon atom of the glucose molecule bearing the aglucon; in the gentiobioside this union is on carbon atom 6. Apparently as a result of the similarity in structure, and because of the $\beta$ configuration of the terminal glucose molecule common to both glycosides, antigens containing either $\mathrm{C}$ or $\mathrm{Ge}$ show reciprocal cross-reactions in the corresponding antisera. The position of linkage of hexose to hexose is apparently less important in determining specificity than is the configuration of the terminal hexose. The configuration of the individual carbon atoms of the terminal hexose is also an important factor in determining specificity, since an antigen containing $\mathrm{L}$ does not react in $\mathrm{C}$ antiserum despite the fact that the structures of $\mathrm{C}$ and $\mathrm{L}$ are identical save in respect to the spatial arrangement of the $\mathrm{H}$ and $\mathrm{OH}$ groups on the fourth carbon atom of the terminal hexose.

Although the M-test antigen fails to precipitate either in C- or Geantiserum, it is a striking fact that both $\mathrm{C}$ - and Ge-test antigens precipitate in an antiserum prepared by immunization with maltosideglobulin. When one considers these cross-reactions with reference to the chemical structure of the three glycosides, it appears that the specificity of the immunological response is more sharply defined when the terminal hexose in the antigenic molecule has the $\beta$ rather than the $\alpha$ configuration. The reason for this is not known.

It has been previously pointed out that the four glycosides, M, C, $\mathrm{Ge}$, and $\mathrm{L}$, each possess in common a large molecular grouping; namely, a glucose molecule bearing the aglucon $-\mathrm{C}_{6} \mathrm{H}_{4}-\mathrm{N}=\mathrm{N}-$. In view of this fact one might expect the corresponding antisera to show marked cross-reactions with test antigens containing any one of the heterologous glycosides. That this is not the case, however, is evident from the results of the precipitin tests given in Table II. It may be concluded, therefore, that the large grouping common to all the disaccharide antigens exerts but little influence on serological crossing and that in those instances in which this phenomenon occurs the reactions are determined primarily by similarities in the configuration of the terminal hexose of the glycosides. 
One striking exception, however, has been encountered in the case of the lactoside, in which the terminal hexose is $\beta$-galactose. An antiserum to the lactoside would, on the basis of the preceding hypothesis, not be expected to precipitate an antigen having a terminal $\beta$-glucose molecule. However, it has been shown that L-antiserum contains precipitins reactive with $\mathrm{C}$-test antigen, although the reaction is not reciprocal. There is at present no adequate explanation for this phenomenon. It may be pointed out that Landsteiner and Lampl (4) encountered a series of non-reciprocal reactions in the course of investigations on the specificity of antisera to $o$-aminobenzene sulfonic acid, and $o$-aminobenzoic acid. Similarly Heidelberger and Kendall (5) have described in detail an analogous series of non-reciprocal precipitin reactions employing antisera prepared by immunization of rabbits with $\mathrm{R}$-salt-azo-benzidine-azo-crystalline egg albumin and native crystalline egg albumin.

3. Heterologous Precipitin Reactions of Disaccharide Antigens in Monosaccharide Antisera.- In order to gain further insight into the factors which determine the serological specificity of disaccharide antigens, the latter were tested in the immune sera prepared by the immunization of rabbits with antigens containing the azophenol glycosides of $\alpha$ - and $\beta$-glucose and $\beta$-galactose combined with horse serum globulin. The structural relationship of the hexosides from which the corresponding monosaccharide antigens were prepared is represented by the following graphic formulae:

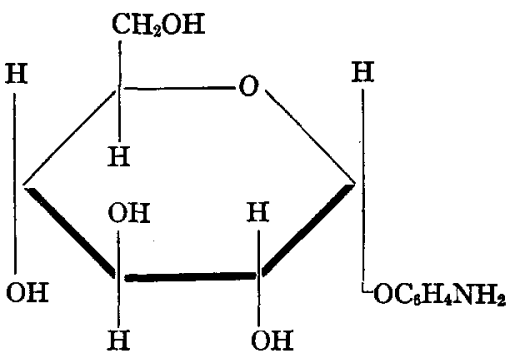

$p$-Aminophenol $\alpha$-glucoside

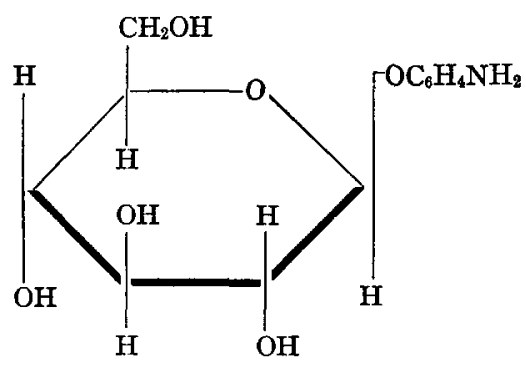

$p$-Aminophenol $\beta$-glucoside 


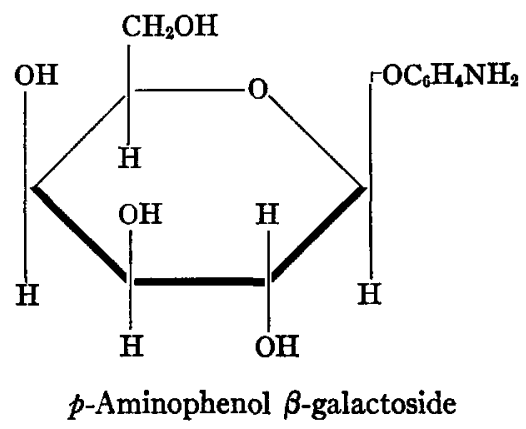

From the above formulae it can be seen that the $\alpha$-and $\beta$-glucosides differ from one another in the stereochemical arrangement of the carbon atom bearing the aglucon. The remaining five carbon atoms of each hexoside have the same stereochemical pattern. The $\beta$-galactoside differs from the $\beta$-glucoside in that in each instance the $\mathrm{H}$ and $\mathrm{OH}$ groups on the fourth carbon atom are interchanged. Before turning to the results of the precipitin tests of the disaccharide test antigens in the monosaccharide antisera, it must be recalled that the terminal hexose of both the cellobioside and the gentiobioside is $\beta$ glucose, while the terminal molecule of the maltoside is $\alpha$-glucose, and of the lactoside, $\beta$-galactose.

From the results of the precipitin reactions of disaccharide antigens in monosaccharide antisera (Table III) it is interesting to observe that only the test antigen containing the maltoside, the terminal hexose of which is $\alpha$-glucose, reacts in $\alpha$-antiserum. The two test antigens containing the cellobioside and gentiobioside, both of which have terminal $\beta$-glucose radicals, react only in $\beta$-antiserum, and finally the lactoside test antigen, the terminal hexose radical of which is galactose, reacts only in $\beta$-galactoside antiserum. The results of these serological tests support the view that the stereochemical configuration of the terminal hexose in disaccharide antigens is the dominant factor in determining their serological crossing in monosaccharide antisera.

4. Precipitin Reactions of Monosaccharide Antigens in Disaccharide Antisera-In order to determine whether the monosaccharide test antigens react with the disaccharide antisera, the latter were tested for the presence of precipitins reactive with $\alpha$-, $\beta$ - and Ga-test antigens. The results of the precipitin tests are given in Table IV. From 
the results given in Table IV it may be seen that only the $\alpha$-test antigen reacts in $M$-antiserum, whereas the $\beta$-test antigen reacts in both

TABLE III

Precipitin Reactions of Disaccharide Antigens in Monosaccharide Antisera

\begin{tabular}{|c|c|c|c|c|c|c|}
\hline \multirow{2}{*}{$\begin{array}{l}\text { Antisera prepared by } \\
\text { immunization with! }\end{array}$} & \multirow{2}{*}{\multicolumn{3}{|c|}{ Test antigens }} & \multicolumn{3}{|c|}{ Final dilution of test antigens } \\
\hline & & & & $1: 5,000$ & $1: 10,000$ & $1: 20,000$ \\
\hline$\alpha$-Globulin & $\begin{array}{l}\alpha \\
\mathrm{C} \\
\mathrm{M} \\
\mathrm{L} \\
\mathrm{Ge}\end{array}$ & $\begin{array}{c}\text { Chick } \\
\text { " } \\
\text { “ } \\
\text { " }\end{array}$ & $\begin{array}{l}\text { erum } \\
، \\
، \\
، \\
،\end{array}$ & $\begin{array}{c}+++ \\
\pm \\
++ \pm \\
0 \\
0\end{array}$ & $\begin{array}{c}++ \pm \\
0 \\
++ \pm \\
0 \\
0\end{array}$ & $\begin{array}{c}++ \pm \\
0 \\
++ \\
0 \\
0\end{array}$ \\
\hline$\beta$-Globulin & $\begin{array}{l}\beta \\
\mathrm{C} \\
\mathrm{M} \\
\mathrm{L} \\
\mathrm{Ge}\end{array}$ & $\begin{array}{c}\text { Chick } \\
\text { " } \\
\text { " } \\
\text { “ }\end{array}$ & $\begin{array}{l}\text { erum } \\
\text { " } \\
\text { " }\end{array}$ & $\begin{array}{c}+++t \\
+++ \\
\pm \\
0 \\
+++\end{array}$ & $\begin{array}{c}+++t \\
++ \pm \\
0 \\
0 \\
+++\end{array}$ & $\begin{array}{c}+++ \pm \\
++ \\
0 \\
0 \\
++\end{array}$ \\
\hline Ga-Globulin & $\begin{array}{l}\mathrm{Ga} \\
\mathrm{C} \\
\mathrm{M} \\
\mathrm{L} \\
\mathrm{Ge}\end{array}$ & $\begin{array}{c}\text { Chick } \\
\text { “ } \\
\text { “ } \\
\text { “ }\end{array}$ & $\begin{array}{l}\text { erum } \\
\text { " } \\
\text { “ } \\
\text { " }\end{array}$ & $\begin{array}{c}+++ \\
0 \\
0 \\
+ \pm \\
0\end{array}$ & $\begin{array}{c}++ \pm \\
0 \\
0 \\
++ \\
0\end{array}$ & $\begin{array}{c}++ \\
0 \\
0 \\
++ \\
0\end{array}$ \\
\hline
\end{tabular}

TABLE IV

Precipitin Reactions of Monosaccharide Antigens in Disaccharide Antisera

\begin{tabular}{|c|c|c|c|c|c|c|c|c|c|}
\hline \multirow{2}{*}{$\begin{array}{l}\text { Antisera prepared by } \\
\text { immunization with: }\end{array}$} & \multicolumn{3}{|c|}{$\begin{array}{c}\text { Final dilution of } \alpha \\
\text { chicken serum antigen }\end{array}$} & \multicolumn{3}{|c|}{$\begin{array}{c}\text { Final dilution of } \beta \\
\text { chicken serum antigen }\end{array}$} & \multicolumn{3}{|c|}{$\begin{array}{l}\text { Final dilution of } \mathrm{Ga} \\
\text { chicken serum antigen }\end{array}$} \\
\hline & 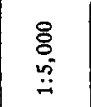 & 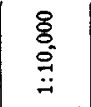 & 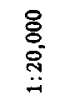 & 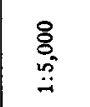 & $\begin{array}{l}\stackrel{8}{8} \\
\stackrel{-}{3} \\
\stackrel{-}{-1}\end{array}$ & 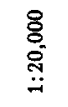 & 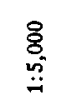 & $\begin{array}{l}\stackrel{8}{0} \\
\stackrel{0}{0} \\
\stackrel{-1}{*}\end{array}$ & 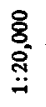 \\
\hline C-Globulin. . . & \pm & \pm & \pm & ++ \pm & ++ & ++ & 0 & 0 & 0 \\
\hline M $\quad$ " & $+t+$ & +++ & ++ & +++ & ++ \pm & ++ & 0 & 0 & 0 \\
\hline$\ldots$ & 0 & 0 & 0 & 0 & 0 & 0 & ++ & + \pm & + \\
\hline $\mathrm{Ge} \quad "$ & \pm & \pm & \pm & ++ \pm & $+t \pm$ & ++ & 0 & 0 & 0 \\
\hline
\end{tabular}

C- and in Ge-antiserum as well as in M-antiserum. It has been previously shown that both $\mathrm{C}$ - and Ge-test antigens, the carbohydrate radicals of which both contain a terminal $\beta$-glucose molecule, react in 
M-antiserum. It is not surprising therefore, that an antigen containing a monosaccharide radical having the $\beta$-glucose configuration also reacts in the same serum. It is also evident from Table IV that the Ga-test antigen, which possesses a terminal $\beta$-galactose molecule, reacts only in L-antiserum. These serological findings again emphasize the fact that the configuration of the terminal hexose is a dominant factor in determining the specificity of antibodies induced by disaccharide antigens.

TABLE V

Inhibition of Precipitins in Cellobioside-Globulin Antiserum by Homologous and Heterologous Glycosides*

\begin{tabular}{l|c|c|c}
\hline \multirow{2}{*}{ Inhibiting glycoside } & \multicolumn{3}{|c}{ Test antigens (final dilution 1:5,000) } \\
\cline { 2 - 4 } & $\mathrm{C}$ & $\mathrm{Ge}$ & $\beta$ \\
\hline None & ++++ & ++ & ++ \pm \\
$\alpha$ & ++++ & + \pm & ++ \\
$\beta$ & ++++ & 0 & 0 \\
$\mathrm{Ga}$ & ++++ & ++ & ++ \\
$\mathrm{C}$ & 0 & 0 & 0 \\
$\mathrm{M}$ & +++ \pm & + \pm & ++ \\
$\mathrm{L}$ & +++ \pm & + \pm & ++ \pm \\
$\mathrm{Ge}$ & +++ \pm & 0 & 0 \\
\hline
\end{tabular}

* The technique of the specific inhibition tests given in Tables V to VIII was as follows: $0.3 \mathrm{cc}$. of a $0.1 \mathrm{M}$ solution of the different $p$-aminophenol glycosides was added to $0.2 \mathrm{cc}$. samples of immune serum. The mixtures were incubated for 2 hours at $37^{\circ} \mathrm{C}$. and to them was then added $0.5 \mathrm{cc}$. of a 1:2,500 dilution of the reactive test antigens. The tubes were again incubated for 2 hours at $37^{\circ} \mathrm{C}$. and the final readings were recorded after the tubes had stood overnight in the ice box.

\section{Specific Inhibition Tests}

1. Cellobioside-Globulin Antiserum.-The selective specificity of the precipitins in cellobioside-globulin antiserum for test antigens containing the cellobioside, the gentiobioside, and the $\beta$-glucoside can be seen from the results of the specific inhibition tests given in Table $\mathrm{V}$.

An analysis of the data presented in Table $V$ shows that the specific reaction between $\mathrm{C}$-antiserum and its homologous test antigen can be inhibited only by $\mathrm{C}$, whereas the cross-reaction of Ge-test antigen in $\mathrm{C}$-antiserum is inhibited by $\mathrm{C}, \mathrm{Ge}$, and by $\beta$. These three glycosides 
each have a terminal $\beta$-glucose radical. It must be pointed out that the heterologous reactions, though somewhat diminished, are not completely inhibited by $\alpha$ or by $M$, both of which are glycosides having a terminal $\alpha$-glucose radical. Likewise the cross-reaction between $\mathrm{C}$ antiserum and Ge-test antigen is not inhibited by $\mathrm{L}$ or by $\mathrm{Ga}$, both of which contain a terminal $\beta$-galactose radical. Similarly, the crossreaction between $\beta$-test antigen and $C$-antiserum is inhibited by $\mathrm{C}$, $\mathrm{Ge}$, and by $\beta$, but by none of the other glycosides.

The results of the specific inhibition tests emphasize the fact that an antigen containing a cellobiose radical gives rise to antibodies which are specific for this particular carbohydrate grouping. Since the reac-

TABLE VI

Inhibition of Precipitins in Gentiobioside-Globulin Antiserum by Homologous and Heterologous Glycosides

\begin{tabular}{c|c|c|c}
\hline \hline \multirow{2}{*}{ Inhibiting glycoside } & \multicolumn{3}{|c}{ Test antigens (final dilution 1:5,000) } \\
\cline { 2 - 4 } & Ge & $\mathrm{C}$ & $\beta$ \\
\hline None & +++ & + \pm & ++ \pm \\
$\alpha$ & ++ \pm & + \pm & ++ \\
$\beta$ & ++ \pm & 0 & 0 \\
Ga & ++ \pm & + \pm & ++ \\
$\mathrm{C}$ & ++ \pm & 0 & 0 \\
$\mathrm{M}$ & ++ \pm & + \pm & ++ \\
$\mathrm{L}$ & ++ \pm & + \pm & ++ \\
$\mathrm{Ge}$ & 0 & 0 & 0 \\
\hline
\end{tabular}

tion between $\mathrm{C}$-antigen and homologous antiserum cannot be inhibited by the glycoside of gentiobiose, a disaccharide which is isomeric with cellobiose, it may be concluded that the position of the biose linkage is important in determining the biological specificity of disaccharide antigens. From the fact that the heterologous reactions of $\beta$ - and Ge-test antigens in $\mathrm{C}$-antiserum can be inhibited only by glycosides containing a terminal $\beta$-glucose molecule, it may be further concluded that the specificity of the serological cross-reactions is determined primarily by the configuration of the terminal hexose residue of the cellobioside.

2. Gentiobioside-Globulin Antiserum.-The results of the specific inhibition of precipitins in gentiobioside-globulin antiserum by the 
homologous and heterologous glycosides are summarized in Table VI. From the results presented in Table VI it can be seen that only the gentiobioside inhibits the reaction between Ge-antiserum and homologous test antigen. The fact that the homologous reaction cannot be inhibited by the cellobioside, a derivative which is identical with the gentiobioside in structure except for the position of the biose junction, further substantiates the importance of the position of intermolecular linkage in determining the specificity of disaccharide antigens. As in the case of the cellobioside antiserum, the heterologous precipitin reactions of Ge-antiserum are in each instance inhibited by glycosides

TABLE VII

Inhibition of Precipitins in Maltoside-Globulin Antiserum by Homologous and Heterologous Glycosides

\begin{tabular}{l|c|c|c|c|c}
\hline \hline \multirow{2}{*}{$\begin{array}{c}\text { Inhibiting gly- } \\
\text { coside }\end{array}$} & \multicolumn{5}{|c}{ Test antigens (final dilution 1:5,000) } \\
\cline { 2 - 6 } & $\mathrm{M}$ & $\alpha$ & $\beta$ & $\mathrm{C}$ & $\mathrm{Ge}$ \\
\hline None & ++++ & ++ \pm & +++ & ++ \pm & ++ \pm \\
$\alpha$ & +++ \pm & 0 & 0 & 0 & 0 \\
$\beta$ & +++ \pm & ++ \pm & 0 & 0 & 0 \\
$\mathrm{Ga}$ & +++ \pm & ++ \pm & +++ & ++ & + \pm \\
$\mathrm{C}$ & +++ \pm & ++ \pm & \pm & 0 & 0 \\
$\mathrm{M}$ & 0 & 0 & 0 & 0 & 0 \\
$\mathrm{~L}$ & +++ \pm & ++ \pm & +++ & ++ & + \pm \\
$\mathrm{Ge}$ & +++ \pm & ++ \pm & 0 & 0 & 0 \\
\hline
\end{tabular}

containing a terminal $\beta$-glucose molecule, and not by those having an $\alpha$-glucose or $\beta$-galactose configuration.

3. Maltoside-Globulin Antiserum.-It will be recalled that an antiserum prepared by immunization with an antigen containing azophenol maltoside cross-reacts with test antigens in which the terminal hexose residue is either $\alpha$ - or $\beta$-glucose, but does not react with antigens in which the terminal hexose is $\beta$-galactose. The results of the specific inhibition of precipitins in $\mathbf{M}$-antiserum by the different glycosides are given in Table VII. From the results of the specific inhibition tests given in Table VII it can again be seen that precipitation of M-test antigen in homologous antiserum is inhibited only by the maltoside. The failure of the other glycosides to inhibit the homolo- 
gous precipitin reaction indicates that the maltoside antigen gives rise to immune bodies specific for the disaccharide radical in question.

It has previously been pointed out that the terminal hexose of maltose is $\alpha$-glucose. The configurational relationship of the six carbon atoms of this portion of the maltoside is in all respects identical with that of the simple monosaccharide derivative, $\alpha$-glucoside. On the basis of this configurational identity, and in view of the fact that the specificity of the cross-precipitins elicited by antigens containing a disaccharide radical is determined primarily by the terminal hexose, the precipitation of azophenol $\alpha$-glucoside in $M$-antiserum may be considered as approaching an homologous reaction. It is therefore to be anticipated that this reaction would be inhibited only by those glycosides possessing an $\alpha$-glucose configuration. That this is indeed the case may be seen by referring to Table VII, the results of which show clearly that neither $\mathrm{B}, \mathrm{Ge}$, nor $\mathrm{C}$ inhibit the reaction of $\alpha$-test antigen in M-antiserum. It may be concluded that the configuration of the terminal hexose of the M-immunizing antigen so orients the specificity of the antibodies induced that the latter, as evidenced by the inhibition tests, remain predominantly specific for the $\alpha$-glucose configuration.

The cross-reactions of $\mathrm{M}$-antiserum with the heterologous test antigens $\beta, \mathrm{C}$, and $\mathrm{Ge}$ can be understood by comparing the similarity in chemical constitution of the three glycosides with that of the homologous maltoside. In each glycoside the terminal hexose is glucose. In the maltoside this hexose has the $\alpha$-configuration, whereas in the $\beta$ glucoside, the cellobioside, and the gentiobioside, the terminal hexose is $\beta$-glucose. In all of these glycosides the five end carbon atoms are identical in stereochemical structure. This identity in structure may explain the cross-reactions of test antigens containing the terminal $\beta$-glucose configuration in $\mathbf{M}$-antiserum. Similarly, it might be expected that test-antigens containing a terminal $\alpha$-glucose molecule would reciprocally react in the antisera prepared by immunization with antigens containing a terminal $\beta$-glucose configuration. It has already been pointed out, however ( $c f$. Table II), that in general this is not the case, although certain $\mathrm{C}$ - and $\mathrm{Ge}$-antisera have been obtained which show a slight degree of crossing with both $\alpha$ - and M-test antigens, when the latter are used in high concentration. It appears, 
therefore, that disaccharide antigens containing a terminal $\beta$-glucose molecule give rise to antibodies which in general cross-react with testantigens having a $\beta$-glucose molecule and not with those in which the terminal hexose has the $\alpha$ configuration. This fact appears to be true only for antigens containing the azophenol glycosides of the $\beta$ disaccharides and not for corresponding glucoside of the monosaccharide, $\beta$-glucose. The reason underlying this unusual phenomenon cannot as yet be defined with certainty. By reference to molecular models of the two disaccharides, maltose and cellobiose, it is at once apparent that the spatial relationship of the polar groups of the two hexoses is in each instance different. This difference in the orientation of these groups may modify, or even mask, the influence which the individual polar groups might otherwise exert upon the specificity of disaccharide antigen containing two hexose molecules.

It has previously been pointed out that the cross-reactions of $\beta$-, $\mathrm{C}$-, and Ge-test antigens in M-antiserum may be attributed to the identity in configuration of the five end carbon atoms of each of these glycosides. It might be expected, therefore, that any glycoside having this common configuration would inhibit the reaction of $\beta-, C_{-}$, or Ge-test antigens in $\mathrm{M}$-antiserum. Indeed, this has proved to be the case, for it may be seen from Table VII that the cross-reactions of the maltoside-globulin antiserum with any one of the heterologous test antigens containing a terminal $\beta$-glucose molecule are inhibited by any one of the $p$-aminophenol glycosides, in which the terminal hexose molecule is glucose, irrespective of its configuration. However, when the configuration of one of the five terminal polar groups is altered, as in the case of the galactoside or lactoside, the latter glycosides fail to inhibit the cross-reactions between $\mathrm{M}$-antiserum and test antigens containing a terminal glucose molecule.

4. Lactoside-Globulin Antiserum.-The selective specificity of the antibodies in lactoside antiserum may be seen from the results of the inhibition tests given in Table VIII.

From data presented in Table VIII, it is seen that the antigen containing the lactoside gives rise to immune bodies which are specific, since the precipitation of L-test antigen in homologous antiserum can be inhibited only by the homologous glycoside. The cross-precipitation of Ga-test antigen in L-antiserum is likewise inhibited only by 
the glycoside of lactose and galactose. This observation once more confirms the view that the terminal hexose of disaccharide antigens exerts a dominant influence in determining serological crossing. On the basis of this concept, it would be expected that L-antiserum would react only with test antigens containing $\mathrm{L}$ and $\mathrm{Ga}$. However, it has already been seen (Table II) that C-test antigen reacts in L-antiserum despite the fact that the terminal hexose of the cellobioside is glucose, while that of the lactoside is galactose. The only portion of the cellobioside and lactoside which is identical in configuration is therefore the glucose molecule bearing the aglucon. The serological activity of $\mathrm{C}$ test antigen in L-antiserum might be ascribed to this common group-

TABLE VIII

Inhibition of Precipitins in Lactoside-Globulin Antiserum by Homologous and Heterologous Glycosides

\begin{tabular}{c|c|c|c}
\hline \hline \multirow{2}{*}{ Inhibiting glycoside } & \multicolumn{3}{|c}{ Test antigens (final dilution 1:5,000) } \\
\cline { 2 - 4 } & $\mathrm{L}$ & $\mathrm{Ga}$ & $\mathrm{C}$ \\
\hline None & +++ & + \pm & ++ \\
$\alpha$ & +++ & + \pm & + \pm \\
$\beta$ & +++ & + \pm & + \pm \\
$\mathrm{Ga}$ & +++ & 0 & + \pm \\
$\mathrm{C}$ & +++ & + \pm & 0 \\
$\mathrm{M}$ & +++ & + \pm & + \pm \\
$\mathrm{C}$ & 0 & + \pm & 0 \\
$\mathrm{Ge}$ & +++ & & + \pm \\
\hline
\end{tabular}

ing. It must be remembered, however, that this grouping is also common to the maltoside and gentiobioside, yet antigens containing the latter glycosides fail to react in L-antiserum. Moreover the two glycosides, Ge and $\mathrm{M}$, do not inhibit the cross-reaction of C-test antigen in L-antiserum. At present there is no adequate explanation for this unusual cross-precipitin reaction, nor do the results of the specific inhibition tests throw any light on the situation. The question must await further investigation before a definite explanation can be given.

\section{DISCUSSION}

In attempting to understand the intricate serological relationships between antigens containing the four disaccharides, gentiobiose, cello- 
biose, lactose, and maltose, it is necessary to have clearly in mind a picture of the stereochemical structure of each disaccharide. The reducing disaccharides, maltose, gentiobiose, lactose, and cellobiose, are compounds of two hexose molecules joined in glycosidic union through the reducing group of one of the monosaccharide constituents. The point of attachment of one hexose to the other, and the nature of the linkage (i.e. whether the terminal hexose has an $\alpha$ or $\beta$ configuration) have been carefully ascertained in the case of the four disaccharides in question, and as a result their chemical structures are fully comprehended. With an exact knowledge of their structures, the disaccharides become excellent substances for study in correlating changes in chemical constitution with differences in biological specificity.

The conversion of these four disaccharides into their corresponding $p$-aminophenol glycosides (3) is without doubt accompanied by no change in the lactal ring structure of the hexose units. The glycosides may be regarded as built up from two units of hexoses in pyranoid form, with the remaining reducing group replaced by the aglucon $-\mathrm{C}_{6} \mathrm{H}_{4} \mathrm{NH}_{2}$. The three glycosides of maltose, cellobiose, and lactose, have a common structure and are distinguishable only in that each has a different configuration. The gentiobioside, on the other hand, differs structurally from its isomers in that the point of attachment of the terminal $\beta$-glucose molecule is on the sixth carbon atom of the glucose molecule bearing the aglucon. By referring to the graphic model formulae these structural and configurational relationships may be clearly seen.

From the results of the specific inhibition tests and the heterologous precipitin reactions it may be seen that these structural and configurational relationships have a distinct and definite influence in determining the immunological specificity of antigens containing these disaccharides. The present study emphasizes the fact that the specificity of the serological cross-reactions of disaccharide antigens is determined by the configuration of the terminal hexose molecule. In a study of the immunological properties of peptides, Landsteiner and van der Scheer (6) have shown that the specificity of antigens containing amino benzoylated peptides depends primarily upon the structure of the terminal amino acid, and to a less degree upon the other amino acids in the peptide chain. 
Although each of the disaccharide antigens contains in common an azophenol $\beta$-glucoside radical, this second hexoside grouping does not appear to be of importance in determining serological crossing; however, its presence does confer upon each antigen certain specific properties. The rôle of this common hexose molecule bearing the aglucon is demonstrated by the fact that the homologous reactions between disaccharide test antigens and the corresponding antisera are not inhibited by simple hexosides conforming in configuration and structure to the terminal hexose molecule of the disaccharide. It must be borne in mind, therefore, that the individual specificity of disaccharide antigens is dependent upon the molecular pattern of the glycoside radical as a whole. Thus it has been shown that antigens containing glycosides as closely related as are the gentiobioside and cellobioside, may be specifically and sharply differentiated serologically by means of inhibition reactions.

From a comparison of the immunological properties of the different disaccharide antigens, it is evident that when the terminal hexose has the $\beta$ configuration the specificity of the antibody response is more sharply defined than when this configuration is of the $\alpha$ type, for it has been shown that although $\mathrm{C}$ - and Ge-test antigens react in $\mathrm{M}$ antiserum, the reverse does not hold true.

A striking analogy to the lack of reciprocal cross-reactions is found in the case of the capsular polysaccharides of Pneumococcus Types III and VIII. It has been observed that the specific polysaccharide of Type VIII Pneumococcus reacts both in Type VIII and Type III antipneumococcus serum, whereas the Type III carbohydrate reacts only in the homologous antiserum.

\section{SUMMARY}

The results of the present study indicate that by means of serological reactions it is possible to differentiate selectively the $p$-aminophenol glycosides of maltose, cellobiose, gentiobiose, and lactose. The immunological specificity of disaccharide-protein antigens prepared from these derivatives, irrespective of the nature of the conjoined protein, is determined by (1) the glycoside molecule as a whole, (2) the configuration of the terminal hexose molecule, and (3) the position of linkage of the two hexose units in the carbohydrate radical. The specific- 
ity of the antibodies induced by the disaccharide antigens appears to be more sharply defined when the configuration of the terminal hexose is of the $\beta$ rather than of the $\alpha$ type.

\section{BIBLIOGRAPHY}

1. (a) Goebel, W. F., and Avery, O. T., J. Exp. Med., 1929, 50, 521. (b) Avery, O. T., and Goebel, W. F., J. Exp. Med., 1929, 50, 533.

2. (a) Goebel, W. F., Babers, F. H., and Avery, O. T., J. Exp. Med., 1932, 55, 761. (b) Avery, O. T., Goebel, W. F., and Babers, F. H., J. Exp. Med., 1932, 55, 769.

3. Babers, F. H., and Goebel, W. F., J. Biol. Chem., 1934, 105, 473.

4. Landsteiner, K., and Lampl, H., Biochem. Z., 1918, 86, 343.

5. Heidelberger, M., and Kendall, F. E., J. Exp. Med., 1934, 59, 519.

6. Landsteiner, K., and van der Scheer, J., J. Exp. Med., 1932, 55, 781; 1934, 59, 769. 